\title{
Review of Challenges and Research Opportunities for Voltage Control in Smart Grids
}

Sun, Hongbin; Guo, Qinglai; Qi, Junjian; Ajjarapu, Venkataramana; Bravo, Richard; Chow, Joe; Li, Zhengshuo; Moghe, Rohit; Nasr-Azadani, Ehsan; Tamrakar, Ujjwol

Total number of authors:

15

Published in:

IEEE Transactions on Power Systems

Link to article, DOI:

10.1109/TPWRS.2019.2897948

Publication date:

2019

Document Version

Peer reviewed version

Link back to DTU Orbit

Citation (APA):

Sun, H., Guo, Q., Qi, J., Ajjarapu, V., Bravo, R., Chow, J., Li, Z., Moghe, R., Nasr-Azadani, E., Tamrakar, U., Taranto, G. N., Tonkoski, R., Valverde, G., Wu, Q., \& Yang, G. (2019). Review of Challenges and Research Opportunities for Voltage Control in Smart Grids. IEEE Transactions on Power Systems, 34(4), 2790-2801. https://doi.org/10.1109/TPWRS.2019.2897948

\section{General rights}

Copyright and moral rights for the publications made accessible in the public portal are retained by the authors and/or other copyright owners and it is a condition of accessing publications that users recognise and abide by the legal requirements associated with these rights.

- Users may download and print one copy of any publication from the public portal for the purpose of private study or research.

- You may not further distribute the material or use it for any profit-making activity or commercial gain

- You may freely distribute the URL identifying the publication in the public portal 


\title{
Review of Challenges and Research Opportunities for Voltage Control in Smart Grids
}

\author{
IEEE-PES Task Force on Voltage Control for Smart Grids \\ Hongbin Sun, Fellow, IEEE, (Chairman), Qinglai Guo, Senior Member, IEEE (Co-chairman), Junjian Qi, Senior \\ Member, IEEE (Secretary), Venkataramana Ajjarapu, Fellow, IEEE, Richard Bravo, Senior Member, IEEE, Joe \\ Chow, Fellow, IEEE, Zhengshuo Li, Member, IEEE, Rohit Moghe, Member, IEEE, Ehsan \\ Nasr-Azadani, Member, IEEE, Ujjwol Tamrakar, Student Member, IEEE, Glauco N. Taranto, Senior \\ Member, IEEE, Reinaldo Tonkoski, Senior Member, IEEE, Gustavo Valverde, Senior Member, IEEE, Qiuwei \\ $\mathrm{Wu}$, Senior Member, IEEE, and Guangya Yang, Senior Member, IEEE
}

\begin{abstract}
In this paper, we review the emerging challenges and research opportunities for voltage control in smart grids. For transmission grids, the voltage control for accommodating wind and solar power, fault-induced delayed voltage recovery (FIDVR), and measurement-based Thévenin equivalent for voltage stability analysis are reviewed. For distribution grids, the impact of high penetration of distributed energy resources (DER) is analyzed, typical control strategies are reviewed, and the challenges for local inverter Volt-Var control is discussed. In addition, the motivation, state-of-art, and future directions of the coordination of transmission system operators (TSO) and distribution system operators (DSO) are also thoroughly discussed.
\end{abstract}

Index Terms-Coordination, distributed energy resources (DER), distribution system operators (DSO), renewable, solar, transmission system operators (TSO), voltage control, wind.

\section{INTRODUCTION}

$\mathbf{V}$ OLTAGE control is facing significant challenges with the increasing integration of utility-scale wind/photovoltaic

H. Sun and Q. Guo are with the Department of Electrical Engineering, Tsinghua University, Beijing China (e-mails: shb@tsinghua.edu.cn; guoqinglai@tsinghua.edu.cn).

J. Qi is with the Department of Electrical and Computer Engineering, University of Central Florida, Orlando, FL 32816 USA (e-mail: Junjian.Qi@ucf.edu).

V. Ajjarapu is with the Department of Electrical and Computer Engineering, Iowa State University, Ames, IA 50011 USA (e-mail: vajjarap@iastate.edu).

R. Bravo is with Southern California Edison (e-mail: Richard.Bravo@sce.com).

J. Chow is with the Department of Electrical, Computer, and Systems Engineering, Rensselaer Polytechnic Institute, Troy, NY 12180 USA (e-mail: chowj@rpi.edu).

Z. Li is with the Department of Electrical Engineering, Southern Methodist University, Dallas, TX 75275 USA (e-mail: shuozhengli@sina.com).

R. Moghe is with Varentec, Santa Clara, CA 95054 USA (e-mail: rmoghe@varentec.com).

E. Nasr-Azadani is with Microsoft Corporation, Redmond, WA 98052 USA (e-mail: ehsan.nasr@microsoft.com).

U. Tamrakar and R. Tonkoski are with the Department of Electrical Engineering and Computer Science, South Dakota State University, Brookings, SD 57007 USA (e-mails: ujjwol.tamrakar@sdstate.edu; reinaldo.tonkoski@sdstate.edu).

G. N. Taranto is with the Department of Electrical Engineering, Federal University of Rio de Janeiro, Rio de Janeiro, RJ 21941 Brazil (e-mail: tarang@coep.ufrj.br).

G. Valverde is with the Power System Laboratory at ETH Zurich, Physikstrasse 3, 8092 Zurich CH, and the University of Costa Rica, 11501-2060 CR (e-mail: gustavo.valverde@ucr.ac.cr).

Q. Wu and G. Yang are with the Centre for Electric Power and Energy, Department of Electrical Engineering, Technical University of Denmark (emails: qw@elektro.dtu.dk; gyy@elektro.dtu.dk).
(PV) farms to transmission grids and various distributed energy resources (DER) in distribution grids. This is leading to major transformations of control schemes that require more sophisticated coordinations and interactions among controllers.

In transmission network (TN), there are many emerging challenges, including but not limited to voltage fluctuation, cascading tripping faults [1], and voltage stability issues such as fault-induced delayed voltage recovery (FIDVR). It will require a better understanding of the interaction between the existing TN and the renewable generation [2], advanced control methods that enable fast participation of renewable generation [3], computationally tractable approaches to help mitigate FIDVR [4], and also improved situational awareness about voltage instability through measurement-based approaches using phasor measurement unit (PMU) data [5].

In distribution network (DN), the high penetration of DER, such as wind or residential PV, has a very high impact on power quality, more specifically on voltage control [6], [7], which will be discussed in Section III-A. Although various control strategies have been proposed [8], [9], there are still many challenges that need to be addressed in the near future such as proper selection and trade-off of different control architectures, adequate parameter settings of local controllers, and the cost-effective coordination of a large number of DER to control voltages while minimizing generation curtailment.

In addition, due to the increasing coupling between the TN and DN, the transmission system operators (TSO) and distribution system operators (DSO) have to be properly coordinated for effective voltage regulation on both sides. This will be a major challenge as reactive power sources connected to the $\mathrm{TN}$ are replaced by DER in the DN, and will require more active participation of DNs on voltage support of TNs.

In order to tackle the above-mentioned challenges on voltage control in smart grids, it is urgently required a better understanding of the emerging problems, and more importantly, the development of more advanced voltage control methods. This paper presents a thorough review of the major challenges, different voltage control schemes that have been proposed to address these challenges, the coordinations between different voltage levels and control centers, and also potential research directions. This non-exhaustive review is based on the experience and concerns of the contributors of the IEEE-PES Task Force on voltage control for smart grids, and it serves as a basis to introduce the ongoing problems and future research 
opportunities on voltage control.

\section{Voltage Control in TRAnSmission Grids}

Optimal voltage control has long been successfully implemented in TNs, including the three-level hierarchical automatic voltage control (AVC) in Europe [10]-[13], the adaptive zone division method in China [14], and the securityconstrained optimal power flow (SCOPF) in PJM, U.S. [15]. The OPF-based formulations lead to solving challenging nonlinear, nonconvex problems that require the use of convex relaxation techniques [16], [17]. This topic has gained a lot of attention and future advances in this field are expected.

Facing emerging challenges such as large-scale wind/solar power integration, the voltage control method needs to be improved. Besides, it may not be sufficient to just maintain acceptable voltage profiles in the system. It is also important to maintain voltage stability that depends on proper volt/var control. Voltage instability includes both short-term and longterm aspects. Short-term voltage instability generally is related to induction motor stalling and is addressed in Section II-B. Long-term voltage stability is discussed in Section II-C.

\section{A. Voltage Control to Integrate Wind Power and Solar PV}

In TNs, one major challenge for high wind power penetration is the significantly increased risks of voltage fluctuation and cascading tripping. Fig. 1 shows the power and voltage of a wind farm named QLS during a typical cascading failure based on historical phasor measurement unit (PMU) data. To address this challenge, a hierarchical "autonomous-synergic" voltage controller is designed for the wind farm [2]. Three voltage control modes, corrective control, coordinated control, and preventive control, are proposed for different operational requirements: 1) Corrective control maintains the terminal voltage of wind turbine generators (WTGs) within their operational limits; 2) Coordinated control tracks the set value and mitigates voltage fluctuations considering all necessary operational constraints; 3) Preventive control reserves more fast-response dynamic reactive power (DRP), on the premise of maintaining the WTGs' terminal voltages and the high-side voltage within a certain threshold.

In [18] reactive power resources are coordinated to enhance the voltage stability of grid-connected wind farms. Methods are also proposed to reserve more DRP in wind farms [19], considering the dynamics of wind farms by heuristic dynamic programming [20] or based on the PI-regulator for the wind farms' secondary voltage control [21]. In [3], an autonomous wind farm voltage control based on model predictive control (MPC) is proposed to maintain the voltage within operational limits and maximize the DRP reserve. To deal with the high $\mathrm{R} / \mathrm{X}$ ratio of the wind farm collector, a combined active and reactive power control is proposed based on MPC [22].

At system level, the mechanism of cascading trip faults has been analyzed [23]. Once such a fault occurs and propagates in wind farms, the voltage will significantly increase within 2-3 seconds. It is thus more reasonable for wind farms to take preventive controls [2]. The boundary of voltage security region (VSR) is computed by an approximate linearization method [24], [25]. Then a robust VSR [26] is proposed in

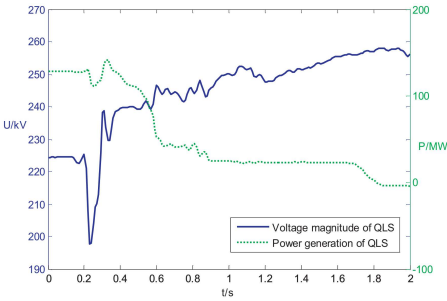

Fig. 1. Typical trip-off process voltage and power of a wind farm [2].

order to consider wind power forecast error. To determine an independent voltage control range for each wind farm, autonomous voltage security region (AVSR) is proposed [27]. In extreme scenarios with very high wind power penetration, insufficient DRP reserves may result in significant wind power curtailment. To address this challenge, an AVSR-based DRP reserve optimization is proposed so that wind power can be accommodated as much as possible [28].

Similar issues also exist for large-scale solar PV integration in TNs. A supervisory voltage control strategy is proposed in [29] to enhance the voltage stability in PV systems by a reactive current division algorithm and online supervisory coordination. In [30] the fault ride-through capabilities in utility-scale PV integration are enhanced using the overload capability of grid-tied inverters. A centralized sequence control strategy is designed to reduce the voltage unbalance factor and keep the PVs' terminal voltages within a certain range by effectively utilizing the capacity of grid-tied inverters [31].

In addition, more wind power, offshore or onshore, has been connected to TN through HVDC lines. Compared with HVAC, HVDC operation is more complicated. The cascading trip faults caused by HVDCs such as by DC-blocking contingency is a major concern [32]. Addressing the local volt/var control complexity in DC converter stations will be challenging. Moreover, HVDCs have var regulation capabilities and can provide fast-response voltage support. Utilizing this to alleviate voltage control problems such as frequent adjustment of the discrete devices [33] is also an interesting topic.

\section{B. Fault-Induced Delayed Voltage Recovery (FIDVR)}

FIDVR issues are mainly caused by the stalling of air conditioner compressors due to low voltages. Their reactive power demand can increase more than 12 times until their internal thermal protection removes them from the grid [34].

The WECC/NERC planning standards have defined criteria on post-fault voltage recovery performance [35]. The percentage voltage deviation on bus $j=1, \ldots, N$ at time $t$ for contingency $k$ among $K$ contingencies can be calculated as:

$$
r_{j}^{k}(t)=\left|\frac{V_{j}(t)-V_{j}^{\text {init }}}{V_{j}^{\text {init }}}\right| \times 100 \%,
$$

where $N$ is the number of buses and $V_{j}^{\text {init }}$ is the pre-fault initial voltage magnitude of bus $j$. The following criteria are usually considered for the post-fault voltage trajectories:

$$
\begin{aligned}
& S_{1}: r_{j}^{k}(t) \leq R_{1} \text { for } t_{\mathrm{cl}} \leq t \leq t_{\mathrm{s}} \\
& S_{2}: T_{r_{j}^{k}}(t) \geq R_{2} \leq D \text { for } t_{\mathrm{cl}} \leq t \leq t_{\mathrm{s}} \\
& S_{3}: r_{j}^{k}(t) \leq R_{3} \text { for } t>t_{\mathrm{s}}
\end{aligned}
$$




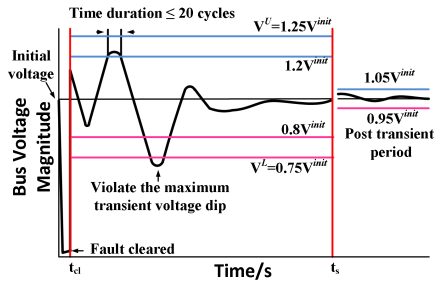

Fig. 2. Post-fault voltage performance criteria for a load bus.

where $t_{\mathrm{cl}}$ is the fault clearing time, $t_{\mathrm{s}}$ is the post-transient time, and $T_{r_{j}^{k}(t) \geq R_{2}}$ is the time duration for $r_{j}^{k}(t) \geq R_{2}$. Typical parameters are $R_{1}=25 \%$ for load buses and $30 \%$ for generator buses, $R_{2}=20 \%, D=1 / 3$ second, $R_{3}=5 \%$, and $t_{\mathrm{s}}=3$ second [35]. For a load bus, the post-fault voltage trajectory and criteria $S_{1}-S_{3}$ are illustrated in Fig. 2.

To effectively and economically mitigate FIDVR, it needs to determine the optimal placement and sizing of dynamic var sources such as static var compensators (SVCs) and static synchronous compensators (STATCOMs) as well the incorporation of volt/var support from DER. Placement and sizing are usually solved separately, but can also be solved simultaneously as a sequence of mixed integer programming problems [36]. For placement, the key is to determine which candidate locations can best improve FIDVR prevention and post-fault voltage recovery. It is challenging mainly because 1) the input-state behavior can be highly nonlinear and complicated, 2) the post-fault trajectory requires solving differentialalgebraic equations, 3 ) the placement depends on the selection of contingencies, and 4) the computational burden increases as the number of var sources grows. DER could potentially prevent FIDVR by not allowing the voltage during remote fault conditions to deepen low enough to cause air conditioner compressors to stall. The post-fault voltage recovery can be achieved by calculating a voltage sensitivity index for selected contingencies [37], [38] or by using the empirical controllability covariance that can consider the nonlinear dynamics and reduce the dependency on the selection of contingencies [39].

The optimal sizing problem is very challenging because 1) it is a non-linear, non-convex optimization problem due to the geometric characteristics of its solution space [4], 2) checking the constraints requires the post-fault voltage trajectories that can only be obtained by solving a power system differentialalgebraic equation model [39]. It is usually formulated as a mixed integer programming problem and addressed by interfacing a heuristic optimization algorithm with power system simulation. For large systems, the computational complexity is high and the solution can easily converge to local optima.

The optimization problem is solved by interfacing branchand-bound and multi-start scatter algorithms [40] or a Matlabbased toolbox KNITRO [41] with power system time domain simulation. Other approaches include multi-objective evolutionary algorithm MOEA/D [42], heuristic optimization [43], particle swarm optimization [44], heuristic linear programming [45], and Voronoi diagram [46]. In [4], the geometric characteristics of the solution space is investigated and the Voronoi diagram method is integrated with linear programming. Ad- dressing the high computational complexity and solving the optimization problem by exploring the unique features of the problem are still an important research direction.

\section{Thévenin Equivalent for Voltage Stability Analysis}

One method to analyze the voltage stability of a load center is to model its power supply with a fixed impedance to a voltage source, which can be presented by a Thévenin equivalent. It can be easily obtained from simulation by increasing load. From impedance matching principle, the maximum power delivery occurs when the load impedance magnitude equals the Thévenin equivalent impedance, based on which voltage stability margin can be readily computed.

Thévenin equivalent computation becomes difficult when using measured data. The challenges include measurement noise, small load variations, and generator excitation system voltage adjustment as loads vary (the last leading to a variable Thévenin voltage as a function of time). A survey of methods, mostly based on PMU data, for long-term voltage instability detection was given in [5]. There are several documented schemes in computing Thévenin equivalent from data.

1) Measured data is fitted to the active power-voltage curve (PV curve) of the Thévenin equivalent by the least mean squares method [47], [48]. This method is suitable for PMU data obtained from disturbances.

2) In [49] a real-time algorithm estimates the Thévenin equivalent seen from a given bus through local PMU data, providing high-speed increase/decrease (due to perceptible system load variations) of Thévenin equivalent parameters, until reaching their new values. This allows a fast and continuous tracking of the evolving Thévenin parameters when voltage instability is approaching.

3) The Thévenin reactance is estimated, from which the Thévenin voltage can be computed. This method can be applied off-line to get a general trend of the Thévenin equivalent, and on-line to track the variation of the Thévenin equivalent in a finer time scale. This method has been applied to a wind hub in a $230-\mathrm{kV}$ system [50].

All three methods are applicable to both on-line and offline estimation. In off-line estimation, longer data windows are used. The calculation methods remain the same.

For future research, one major challenge is how to properly verify and validate these measurement-based methods by extensive testing using measured SCADA and PMU data from power systems. In addition, another challenge is to develop methods to effectively extract Thévenin equivalent voltage and impedance for measured data in ambient conditions that only show small variations in power and voltage magnitude.

\section{Voltage Control in Active Distribution Grid}

The interconnection of high penetration levels of DER will change the distribution grid's loading patterns, influencing the performance of voltage regulation devices. The difficulties in coordinating voltage regulation devices under high distributed generation (DG) penetration are driving utilities to have more stringent grid connection requirements. For instance, in Germany the EN50160 standard dictates that the voltage should remain within $\pm 10 \%$ of the 10 -min average of the RMS value [51], [52]. At the medium voltage (MV) level, and for 
the units rated between $3.68 \mathrm{kVA}$ and $13.8 \mathrm{kVA}$ at the Low Voltage (LV) level, the DG units should be able to vary their power factor from 0.95 (leading) to 0.95 (lagging). In addition, for units rated above $13.8 \mathrm{kVA}$ the power factor should be controllable from 0.90 (leading) to 0.90 (lagging).

In U.S., DG units may regulate active and reactive power with coordination between the system operator and DG operator based on IEEE 1547 [53], [54]. Actually active power adjustments are being mandated to support voltage regulation in IEEE 1547-2018 [54]. The voltage regulation standard is based on the ANSI C84.1-2016 standard's Range A definition [55]. The voltage should be maintained within $\pm 5 \%$ for LV side, and for MV side the upper and lower limits are, respectively, $+5 \%$ and $-2.5 \%$. Hawaiian electric is proposing voltage criteria of $\pm 2.5 \%$ for day-time and $+5 \% /-2.5 \%$ for evening for MV networks to accommodate future DG growth [56]. In Ontario, Canada, for DG units rated over $30 \mathrm{kVA}$ the power factor has to be controllable between 0.95 (leading) to 0.95 (lagging) and the Hydro one LV voltage should be within $\pm 6 \%$ [57]. The participation of DER on voltage control depends on their reactive power capability and active power modulation. Accordingly, the system behavior in response to small or large disturbances may be different for various DER technologies.

Further in this section, the major voltage challenges associated with high DER penetration are discussed in Section III-A. Section III-B categorizes and summarizes various type of voltage control methods for DG units and Electric Vehicles (EVs). Whereas, Section III-C summarizes the voltage control techniques for microgrids. Going further, Section III-D discusses the challenges of real-time smart inverter based volt/var control (VVC) recommended by the integration standard IEEE15472018. To address challenges of smart inverter, the new type of VVC devices are discussed in Section III-E.

\section{A. Voltage Issues Due to High DER Penetration}

High DG penetration and integration of EVs lead to the following issues in distribution systems.

1) Voltage rise: A known issue from DSOs is voltage rise when PV production is high, particularly at the far end of the LV feeders [58], [59], which can lead to conservative limits on $\mathrm{PV}$ installation. The high $\mathrm{R} / \mathrm{X}$ ratio in $\mathrm{LV}$ systems makes the voltage magnitude more sensitive to the active power injection than to reactive power. This is exactly opposite to the high voltage grids for which the $\mathrm{R} / \mathrm{X}$ ratio is low and the grid operator uses reactive power to regulate voltage.

In Fig. 3, PV is injecting power to the system through a series impedance representing the electric distance between the PV plant and the Thévenin voltage of the grid. This impedance is certainly not constant in reality, depending on the power flow, grid configuration, etc. The analysis here serves as a qualitatively illustration of the voltage characteristics in different grids, and is applicable for all DG units. Assume the receiving end voltage $\dot{V}_{T}$ is at the standard position (voltage angle is zero), the expression of the voltage drop across the series impedance is:

$\Delta \dot{V}=\left(\frac{P+j Q}{V_{T}}\right)^{*}(R+j X)=\frac{P R+Q X}{V_{T}}+j \frac{P X-Q R}{V_{T}}$.

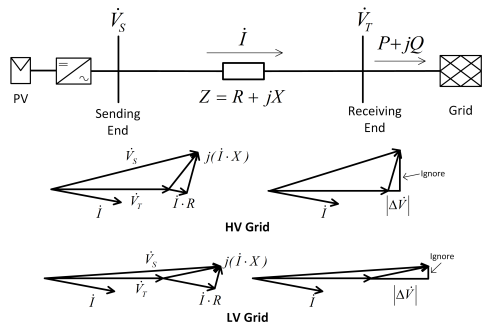

Fig. 3. The principle of voltage characteristics.

In systems with low $\mathrm{R} / \mathrm{X}$ ratios, the voltage drop can be expressed by ignoring the resistance effect:

$$
\Delta \dot{V}=\frac{Q X}{V_{T}}+j \frac{P X}{V_{T}},
$$

where the magnitude drop $|\Delta \dot{V}|$ can be approximated by ignoring the imaginary component. In high $\mathrm{R} / \mathrm{X}$ ratio systems, the effect of resistance is significant. Instead, the magnitude drop $|\Delta \dot{V}|$ in LV system may be approximated by

$$
|\Delta \dot{V}|=\frac{P R+Q X}{V_{T}} .
$$

Suppose the voltage at the substation is constant, an increment of active power transmission from PV to the substation will increase the sending end voltage. By applying negative reactive power increment, this voltage magnitude difference may be reduced. To regulate voltage, the PV plant can reduce active power injection or apply negative reactive power injection as required by the IEEE 1547-2018 [54]. If reactive power cannot sufficiently regulate voltage, active power control could be implemented with controllable loads such as heat pumps, EVs, or battery storage. For example, the EV charging points that coordinate with small DG units to control voltage [60], [61]. In [62] a voltage unbalance mitigation strategy is proposed by coordinating PV inverters and demand side management.

2) Voltage drop: This is a classical voltage problem dealt with by DSO. The adoption of EVs will add more challenges, particularly overloads and excessive voltage drops at peak load. These problems will aggravate if vehicle owners have no incentive or information to schedule battery charging for optimized grid utilization [63]. It is required to control their charging rate and time of connections with a fair distribution of efforts among EVs. Moreover, the way charging points will be controlled with limited communication is still searched for.

3) Impact from reversed power flow: Distribution systems are designed to operate for unidirectional power flow. Existing line voltage regulators (LVRs) usually correct voltage drop on the load side. Voltage is sensed at the load-side of the LVR and taps are adjusted to correct the load-side voltage. When DER is back-feeding a voltage regulator, the regulator will change taps to correct voltage. In addition to the feeding main grid, as local current sources DER can also control the local voltage by manipulating their currents. If LVR operates in constant-voltage mode, it will decrease load-side voltage if DER increases it. However, the voltage of DER connection point may still be too high if the number of taps is not adequate or the LVR set-point is determined assuming unidirectional 
power flow and there is distance between LVR and DER. If LVR operates in line-drop-compensation mode, DER can cause significant problems since it will increase the voltage at its secondary-side under reverse flow. This will worsen the situation if there is already voltage rise caused by DER. Even if LVRs are bi-directional, they can only control local voltage. When there is voltage rise due to reversed flow, only the DER and/or voltage regulation devices installed at the DER vicinity can provide full voltage correction between DER and LVR.

4) Voltage fluctuation: Higher voltage fluctuation due to cloud cover variations can lead to poor power quality and high voltage variability across the entire feeder. Further, in the presence of smart inverters, in order to ensure system stability, the volt-var curves are chosen to have higher deadbands $( \pm 3 \%)$ and larger slope $( \pm 3 \%)$ [64]. These factors lead to reduced upper and lower voltage margins in reference to the ANSIA limit (114 V-126 V) for performing conservation voltage reduction (CVR) and Volt-Var control (VVC) functions [65].

B. Local, Decentralized, Distributed, and Centralized Control

Voltage control techniques in the active distribution grid can be classified into four categories: local control, decentralized control, distributed control, and centralized control [6]. Proper selection and trade-off of different control architectures is one major challenge for voltage control.

1) Local voltage control: The control decisions of the DER are made based on local voltage/current measurements at the point-of-interconnection. Voltage control is provided through reactive power control of dispersed DG units, active power curtailment of DG generation, and smart charging of EVs, which can reduce the impact of renewable generation and minimize the need of auxiliary equipment for voltage control [66]-[68]. Although local control techniques do not require communication [69], its inability to align with the utilities' control strategy is the main drawback.

For a simple 2-bus system, the reactive power required to maintain constant voltage for a given increase in active power $\Delta \mathrm{P}$ can be approximated as $\mathrm{Q}=-\Delta \mathrm{P} \cdot \mathrm{R} / \mathrm{X}$, where $\mathrm{R}$ and $\mathrm{X}$ are the resistance and reactance of the branch [70]. One problem is that in $\mathrm{MV}$ and $\mathrm{LV}$ branches the $\mathrm{R} / \mathrm{X}$ ratio tends to be high [71] which results in higher reactive power requirement. This leads to high power rating requirements of inverters and can also increase the losses in the circuit. Active power curtailment (APC) is another viable method to prevent overvoltage [70], in which the output power of inverters that are typically operated at their maximum power point is curtailed. Adaptive techniques such as online adjustment of droop values for APC have been proposed [72], [73]. Other methods incorporate Energy Storage Systems (ESSs) [74] and use a mixture of reactive and active power control strategies [75]. Specific challenges related to real-time local smart inverter control will be discussed in detail later in Section III-D.

2) Decentralized voltage control: It aims at enhancing local control using low-form communication system [76]. This may include coordination among various system components in an automated manner without regulation from the system operator (although some strategies may optionally communicate with the system operator) to optimize local grid operation [66], [77]. A global distress signal is used under overvoltage conditions in [78]. The controller is implemented as a finite-state machine and prioritizes reactive power support over active power curtailment. In [79], a decentralized robust energy management method for distribution networks with renewable DG units is developed based on the alternating direction method of multipliers (ADMM) algorithm.

A multi-agent market based control of EV charging that considers transformer and voltage limitations is presented in [80]. The EV agents communicate simple messages to substation agents. The EVs are charged at minimum cost, without affecting the network and keeping the customer welfare at maximum at all times. Compared with centralized schemes, decentralized schemes can provide flexible, efficient, and robust regulation for smart distribution networks [9].

3) Distributed voltage control: This is a voltage control scheme without a central controller, and implemented with node-local computations using only local measurements augmented with limited information from the neighboring nodes through communication channels [9]. In [81], a two-stage distributed voltage control scheme is proposed. The first stage is the local control of each DG based on sensitivity analysis and the second stage acquires reactive power support from other DG units. In [61], a consensus-based cooperative control is proposed to regulate voltage by coordinating EVs and active power curtailment of PV. In [82], a distributed voltage stability assessment considering DG units is developed based on distributed continuation power flow.

4) Centralized voltage control: Also known as active network management, it utilizes sophisticated communication networks to regulate voltage [83], [84]. State estimation is used to estimate voltage profile, based on which DG and other components are dispatched [85]. Through a coordinated control of on-load tap changer (OLTC), DG, and voltage regulators, a centralized control approach allows optimized operation of the entire region of the grid under the system operator [86], [87]. In [88] a primary cabin (PC) voltage control is proposed for distribution grids, which is a hierarchical control with decentralized functionalities at the PC level and centralized functions in the distribution management system (DMS) for coordination among PC controls. Centralized controllers have also been explored for voltage drop mitigation due to EV charging, including optimization [89], [90] and rule-based options [91]. Centralized control can have better performance than decentralized control due to the optimization of the resources. However, it requires a reliable communication network using protocols such as DNP 3.0 or IEC 61850 with considerable investment in sensors and measurements.

\section{Voltage Control in Microgrids}

Microgrids are subsystems of loads, DER, and ESSs with clearly defined electrical boundaries that can act as a controllable entity. They can disconnect from/connect to grid at the point of common coupling (PCC) to operate in islanded/gridconnected modes. Some countries still apply DG interconnection requirements for microgrids based on IEEE 1547.4 [57].

The microgrid controller is responsible for coordinating DER and loads to achieve desired P/Q or volt/var at PCC. Centralized approaches require a fast, reliable communication 
between DER and the microgrid controller. Controllers utilizing local information may not be suitable for all operating conditions [92]. Distributed approaches relying on limited communication have thus been proposed. Under this context, a hierarchical approach consisting of primary, secondary, and tertiary control is typically employed for voltage control of microgrids [93]. The primary controller is usually a droopbased controller which regulates the voltage through reactive power sharing. The secondary and tertiary controllers are responsible for any steady-state errors [94].

In a weak grid, voltage stability can also be a concern [95]. For example, the operation of microgrids with synchronous machine based DER under unbalanced condition may result in stability issues [96]. If voltage unbalance is not properly compensated by system controls, high power oscillations may appear at double frequency due to negative sequence components, resulting in disconnection [97]. Techniques such as injection of negative sequence components [98] or voltage stabilizers [96] have thus been proposed.

On the other hand, the voltage control in islanded microgrid with high renewable penetration is also challenging. In islanded microgrids, the task of voltage control is attributed to the master controller of the system. Since the $\mathrm{R} / \mathrm{X}$ ratio in microgrids is high, the frequency and voltage control cannot be fully decoupled. Significant, sudden change in renewable generation may lead to voltage and frequency instability, if the voltage and frequency are not properly controlled by gridforming DER and the microgrid controller.

The work in [99] presents a technique for controlling a system of inverters in islanded low-inertia microgrids. The AC output of each inverter is modulated to emulate the dynamics of a nonlinear oscillator. The local controllers only require local measurements available at the $\mathrm{AC}$ terminals. The inverters adjust their power output to match the load while maximizing energy delivery and keeping the steady-state voltages within limits for all loading conditions.

\section{Challenges of Smart Inverter Volt/Var Control (VVC)}

The focus of this section is to discuss the challenges of real-time smart inverter VVC in the context of integration standards such as IEEE 1547 [54]. The earlier version of IEEE 1547 [53] and Rule 21 in California [64] preferred DER to operate in unity power factor mode to avoid unexpected issues. However, their revised versions such as IEEE 1547-2018 include the functionality of local regulation of voltages through inverter VVC [54]. A typical VVC scheme recommended by these standards known as 'droop' VVC is a piecewise linear curve with negative slope. The droop curve allows var injection/absorption for low/high voltages [100]. Due to its simple design and easy implementation, it has been explored by [101]-[104] and recommended by integration standards.

There are several challenges for the droop VVC framework. First major issue is of its vulnerability to control instability due to inappropriate control parameter selection. It has been reported by several studies that the smart inverter parameters need to be determined appropriately based on the feeder configuration and operating conditions such as load profile, solar penetration level, desired voltage set-point, cloud cover etc.; and a slight variation in the settings can yield significantly different responses [105]-[107]. Specifically, VVC is highly sensitive to its droop (slope) parameter and an improper slope selection may lead to control instability or voltage oscillations (voltage flicker) [101], [102], [104]. Another issue with droop VVC is that due to its inherent proportional control design, there is always a compromise between maintaining control stability and achieving set-point tracking accuracy which can potentially lead to voltage violations as shown in [104]. Another major issue is the non-adaptability of the droop VVC in changing conditions which challenges the real-time implementation of the control.

The recent literature has recognized and attempted to address these issues. For instance, delayed VVC [102] improves the control stability but does not discuss the parameter selection and set-point tracking accuracy. A scaled VVC [103] addresses both control stability and set-point tracking. However, it is not compatible with standard droop VVC framework and also requires full centralized topology information. An adaptive droop VVC [104] addresses these issues by making parameter selection self-adaptive to changing operating conditions and external disturbances such as a change in substation voltage, sudden cloud cover, cloud intermittency and sudden load changes. However, this problem of VVC becomes even more complex in a real-world due to thousands of inverter devices operating simultaneously. Addressing these challenges will enable the smart inverters to be utilized to their fullest potential for enhancing the distribution system performance under a wide range of operating conditions.

\section{E. Voltage Control by Low Voltage Var Controllers (LV VCs)}

Smart inverters may inject/absorb vars or inject/curtail watts locally to deal with undervoltage/overvoltage issues. However, inverters are consumer owned assets and utilities do not control where the next smart inverter is installed on the grid [108]. Future controllability of smart inverters would require utilities to integrate them into their SCADA, DMS, or DERMS, either directly or via a system aggregator, which can be challenging. To address these challenges, LV VCs have been developed, which use power electronics-based, fast-acting, decentralized shunt-var technology for voltage regulation. Each device is connected to the secondary-side of a pole- or pad-mounted service transformer to tightly regulate the voltage $( \pm 0.5 \%$ within a set-point) at local and feeder-wide by injecting or consuming 0 to 10 kvar [109]. When the voltage goes below the set-point, the LV VC will inject incremental capacitive vars to boost the voltage; when the voltage goes higher than the setpoint it will remove the incremental capacitive vars to reduce the voltage, thus tightly regulating the local voltage. Further, a cluster of LV VCs have a voltage tightening effect even on the primary MV side which can help regulate the voltage where there are no LV VCs [110]. As utility owned assets, they can not only manage the PV-induced voltage fluctuations and overvoltage issues but can also provide incremental benefits of performing CVR for demand management and energy savings.

LV VCs has been deployed at the 12.47-kV Keolu substation of Hawaiian Electric on the island of O'ahu where there is over $90 \%$ of PV penetration (4.3 MW residential PV) [111]. 
Sixty-one LV VC devices were deployed on two circuits to tighten the voltage by almost $50 \%$, which allowed lowering LTC voltage from $122 \mathrm{~V}$ to $119.5 \mathrm{~V}$ to create an upper voltage headroom (see Fig. 4). The studies have shown that LV VCs could allow Hawaiian electric to increase PV penetration from $90 \%$ to $125 \%$ without causing any curtailment.

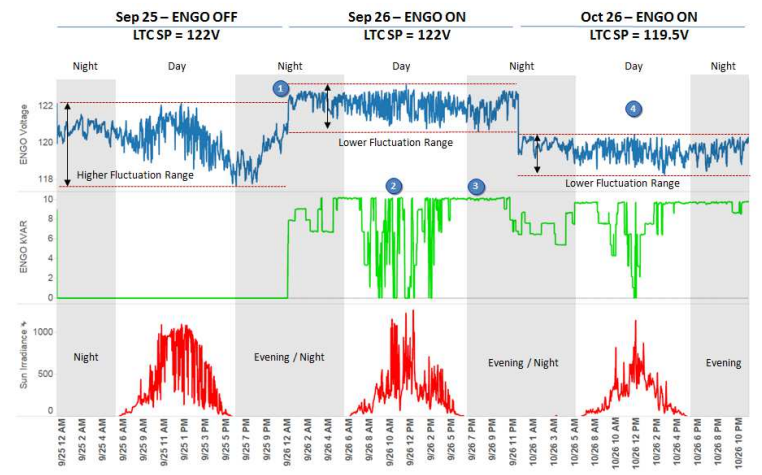

Fig. 4. Top plot: Secondary side voltage; Middle plot: Vars injected by SVC; Bottom plot: Solar Irradiance. Plot is divided into three parts: i) Left most part shows a day when LV VCs are OFF; ii) Middle part shows a day with LV VCs turned ON; iii) Right part shows a day with LTC set-point lowered and LV VCs turned ON with a lower set-point.

\section{Coordinated Voltage Control Considering INTERACTIONS OF TSO AND DSO}

\section{A. Motivation of TSO and DSO Coordination}

About ten years ago, industry and academia noticed the necessity of coordinating TSO and DSO for voltage control. The initial motivation, as demonstrated in the Swiss grid project [112], was to limit reactive power exchange at the transmission-distribution interface when there are scarce reactive power resources in a TN. Then, with DER increasingly integrated, people recognized that a DN with DER has flexibility in adjusting its reactive power consumption to provide reactive power reserves and improve TN voltages [113]-[116]. Due to their geographically distributed nature, if the DER are properly coordinated, they may provide more flexible and localized var support to the bulk system at lower cost than installing var devices in TN [116]. Positive effect of the coordination was verified on a Danish power system [117], and the ENTSOE network code now stipulates that a TSO must retrieve the reactive power reserves of each DSO [118]. Meanwhile, under high DG penetration the reverse power flow caused by DG units unwantedly increases TN voltages and even saturates OLTCs at boundary buses, which leads to the voltages of TN and DN being no longer uncoupled [119]. In this case, TSO and DSO must coordinate to control voltages.

TSO in Great Britain has detected a declining trend of reactive power demand under light load due to less inductive loads and higher DG penetration [120]. Hence, tap staggering in parallel step-down transformers is proposed to reduce reactive power surplus in TNs [121]. Here, an intentional offset in transformer tap positions induces a circulating current that results in reactive power absorption. This is extended in [122] to calculate the optimal transformer tap positions that minimize losses and the number of switching operations.

\section{B. Rule-Based Methods vs Distributed Optimization}

As for coordination methods, both rule-based methods and distributed optimization have been studied. Early work is exemplified in [123]-[125], where an allowable range of the boundary-bus reactive power is sent from DSO to TSO who then determines the boundary-bus reactive power and voltage setpoints. Furthermore, [119] suggested an MPC to be implemented by the DSO in a finer-grained resolution to ensure suitable distribution system voltages while the DSO optimally tracks the boundary-bus reactive power setpoint from TSO. In [126] an MPC-based controller keeps DN voltages within limits by coordinating DG and classical control devices and ensures that the power factor at DN's connection point or the reactive power exchanged with $\mathrm{TN}$ remains within limits.

However, these methods may deteriorate the optimality of a DSO's voltage control target. To resolve this issue, TSO and DSO can repeatedly solve their local voltage control problems and exchange boundary-bus voltage and power until there is feasible power flow [127]. Alternatively, [128] and [129] propose a curve fitting approach to represent the "response" of the optimal value of a DSO's problem regarding possible boundary-bus voltage set-points and incorporate this information into a TSO's problem to produce a boundarybus voltage set-point. Hence, the iterations between TSO and DSO required in [127] are avoided. To ensure that the voltage setpoint given by TSO always leads to feasible DSO operation, a feasibility constraint is included in the TSO's problem [129].

Rule-based methods may not converge, or the converged solution may not be optimal. Distributed optimization theory is thus applied for an effective coordination. The well-known decentralized and iterative algorithms, e.g. APP [130], ADMM [131], AND [132] or OCD [133], are applied, and the generalized Benders decomposition algorithm is also tested in [134], in which a global reactive power optimization model is proposed for transmission and distribution grids. In contrast to those algorithms originally designed for general purposes, the heterogenous decomposition (HGD) algorithm in [135] seizes the heterogeneous TSO-DSO operation features where a TSO oversees the boundary-bus voltage and a DSO supervises the boundary-bus power. It suggests that the boundarybus voltage and power should be determined respectively by TSO and DSO and then be exchanged between them. [135] further analyzes the differences between HGD, APP and OCD algorithms and tested their performance on TSO-DSO coordination. Although these algorithms are more rigorous than heuristic methods, more field tests are needed to validate their robustness against complicated operational conditions.

In [136], a model-free optimal dispatch of controllable DER is proposed to control the power exchange between $\mathrm{TN}$ and DN while maintaining DN bus voltages within limits. It is based on a two-dimensional extremum seeking (ES) control that adds orthogonal sinusoidal perturbations to active and reactive power of controllable DER. It avoids any network model but relies on synchronized measurements of both the DER power output and the measured objective function. 


\section{DN Supporting TN in Emergency Conditions}

As in Section III, many control schemes are proposed to regulate DN voltages. However, most of them rely on a strong (stiff) TN which may not be the case as large disturbances, such as line tripping or generation outages, weaken the TN.

DNs can help TNs by providing fast reactive power injections from multiple DG units. DNs can also reduce their demands by increasing local generation of active (if any) and reactive power, or coordinate DER to avoid the power recovery of voltage sensitive loads after a dramatic TN voltage drop. Restoration of these loads is slow due to OLTC actions and may lead to long-term voltage instability conditions [137].

DN voltage control schemes that ignore the conditions of TNs may precipitate long-term voltage instability due to fast load power recovery activated by fast response of the DG units restoring DN voltages [138]. Additionally, local identification of emergency conditions [139], based on monitoring the unsuccessful attempt of OLTCs to restore DN voltages, could become more difficult, as DG units may temporarily bring DN voltages back to or close to pre-disturbance conditions, hiding the problem faced by the TN. To avoid these problems, an emergency signal from the $\mathrm{TN}$ could be used to temporarily change the DN voltage controller's logic in order to positively help the TN to reach a new long-term equilibrium point.

$\mathrm{DN}$ voltage control that provides support to $\mathrm{TN}$ could also benefit from demand response strategies, as direct control of thermostatically controlled loads (TCLs), EVs and ESSs could temporarily reduce the active/reactive power demands of DNs. The coordination, communication requirements, and how DER participates in voltage control need to be carefully investigated.

\section{Transmission-Distribution (T-D) Co-Simulation}

In order to utilize DER's Volt/Var capability to enhance TN performance, a proper coordination between TSO and DSO is needed. An optimization framework is required which provides ancillary services to $\mathrm{TN}$ while maintaining $\mathrm{DN}$ voltages within the operating limits. In one such attempt, [140] proposes a realtime algorithmic framework which meets the real power demand request from TSO at the feeder substation by controlling DER output. DN voltage limits are enforced via constraints in the optimization. Similarly, [141] minimizes the reactive power demand at the feeder substation using fixed power factor mode of DER. However, all such studies represent the TN as a substation and therefore it is impossible to observe the direct impact of this coordinated control on the grid.

In order to investigate the true impact of DER var support on transmission performance, T-D co-simulation is required [142]. [143] discusses how co-simulation provides more accurate long-term voltage stability assessment with DER penetration compared to only $\mathrm{TN}$ or DN simulation. In conventional TN simulation, the load is aggregated at substation and the full DN topology is not modeled. In conventional DN simulation, the substation voltage is assumed fixed, thus TN's impact on substation is neglected. There have been some recent attempts to develop T-D co-simulation methods and platforms [144][146] but there is still a large scope of customizing utilizing these platforms for the concerned DER Volt/Var application.

\section{E. Future Directions for TSO and DSO Coordination}

The study in [138] shows that a DSO's voltage control affects the static instability of an integrated system. It is thus necessary to take this factor into account when designing a coordination method. However, the conventional TN or DN voltage stability assessment is inaccurate in predicting the long-term (or "static") voltage stability margin of an integrated system, as shown in [142], [143]. A distributed algorithm is proposed in [82] to accurately evaluate the static voltage stability of an integrated system, which conforms to the distributed architecture of coordinated voltage control methods.

Although many distributed coordination methods have been proposed, they need to be further tested. Also, most work does not consider electricity market when designing coordinated voltage control. Since in some systems only a few voltage regulation devices are owned by TSOs, the price mechanisms of dispatching var resources should be considered.

\section{CONCLUSION}

In this paper we perform a thorough review on the emerging challenges and opportunities of voltage control in transmission grid, distribution grid, and on coordinating the TSO and DSO. For TN, voltage fluctuation, cascading trip, and FIDVR are the major challenges. For DN, advanced control strategies are needed to mitigate the impact of DER integration. As for TSODSO coordination, stability and market should be considered.

\section{REFERENCES}

[1] K. Sun, Y. Hou, W. Sun, and J. Qi, Power System Control Under Cascading Failures: Understanding, Mitigation, and System Restoration. Wiley-IEEE Press, 2019.

[2] Q. Guo, H. Sun, B. Wang, B. Zhang, W. Wu, and L. Tang, "Hierarchical automatic voltage control for integration of large-scale wind power: Design and implementation," Electr. Pow. Syst. Res., vol. 120, pp. 234 241, Mar. 2015.

[3] H. Zhao, Q. Wu, Q. Guo, H. Sun, S. Huang, and Y. Xue, "Coordinated voltage control of a wind farm based on model predictive control," IEEE Trans. Sustain. Energy, vol. 7, no. 4, pp. 1440-1451, Oct. 2016.

[4] W. Huang, K. Sun, J. Qi, and J. Ning, "Optimal allocation of dynamic var sources using the Voronoi diagram method integrating linear programing," IEEE Trans. Power Syst., vol. 32, no. 6, pp. 4644-4655, Nov. 2017.

[5] M. Glavic and T. Van Cutsem, "A short survey of methods for voltage instability detection," in IEEE Power and Energy Society General Meeting, Jul. 2011, pp. 1-8.

[6] G. Yang, F. Marra, M. Juamperez, S. B. Kjaer, S. Hashemi, J. Østergaard, H. H. Ipsen, and K. H. Frederiksen, "Voltage rise mitigation for solar PV integration at LV grids," Journal of Modern Power Systems and Clean Energy, vol. 3, no. 3, pp. 411-421, Sept. 2015.

[7] M. H. J. Bollen, R. Das, S. Djokic, P. Ciufo, J. Meyer, S. K. Ronnberg, and F. Zavodam, "Power quality concerns in implementing smart distribution-grid applications," IEEE Trans. Smart Grid, vol. 8, no. 1, pp. 391-399, Jan 2017.

[8] D. E. Olivares, A. Mehrizi-Sani, A. H. Etemadi, C. A. Canizares, R. Iravani, M. Kazerani, A. H. Hajimiragha, O. Gomis-Bellmunt, M. Saeedifard, R. Palma-Behnke, G. A. Jimenez-Estevez, and N. D. Hatziargyriou, "Trends in microgrid control," IEEE Trans. Smart Grid, vol. 5, no. 4, pp. 1905-1919, Jul. 2014.

[9] K. E. Antoniadou-Plytaria, I. N. Kouveliotis-Lysikatos, P. S. Georgilakis, and N. Hatziargyriou, "Distributed and decentralized voltage control of smart distribution networks: Models, methods, and future research," IEEE Trans. Smart Grid, vol. 8, no. 6, pp. 2999 - 3008, Nov. 2017.

[10] M. D. Ilic, X. Liu, G. Leung, M. Athans, C. Vialas, and P. Pruvot, "Improved secondary and new tertiary voltage control," IEEE Trans. Power Syst., vol. 10, no. 4, pp. 1851-1862, Nov. 1995. 
[11] H. Lefebvre, D. Fragnier, J. Boussion, P. Mallet, and M. Bulot, "Secondary coordinated voltage control system: Feedback of EDF," in IEEE Power Engineering Society Summer Meeting, vol. 1, 2000, pp. $290-295$.

[12] S. Corsi, M. Pozzi, C. Sabelli, and A. Serrani, "The coordinated automatic voltage control of the italian transmission grid-Part I: Reasons of the choice and overview of the consolidated hierarchical system," IEEE Trans. Power Syst., vol. 19, no. 4, pp. 1723-1732, Nov. 2004.

[13] S. Corsi, M. Pozzi, M. Sforna, and G. Dell'Olio, "The coordinated automatic voltage control of the italian transmission grid-Part II: Control apparatuses and field performance of the consolidated hierarchical system," IEEE Trans. Power Syst., vol. 19, no. 4, pp. 1733-1741, Nov. 2004.

[14] H. Sun, Q. Guo, B. Zhang, W. Wu, and B. Wang, "An adaptive zonedivision-based automatic voltage control system with applications in China," IEEE Trans. Power Syst., vol. 28, no. 2, pp. 1816-1828, May 2013.

[15] Q. Guo, H. Sun, M. Zhang, J. Tong, B. Zhang, and B. Wang, "Optimal voltage control of PJM smart transmission grid: Study, implementation, and evaluation," IEEE Trans. Smart Grid, vol. 4, no. 3, pp. 1665-1674, Sept. 2013

[16] D. K. Molzahn, J. Holzer, B. Lesieutre, and C. DeMarco, "Implementation of a large-scale optimal power flow solver based on semidefinite programming," IEEE Trans. Power Syst., vol. 28, no. 4, pp. 3987-3998, Nov. 2013.

[17] S. Low, "Convex relaxation of optimal power flow part i: Formulations and equivalence," IEEE Trans. Control Netw. Syst., vol. 15, no. 1, pp. 15-27, Mar. 2014

[18] V. S. S. Kumar, K. K. Reddy, and D. Thukaram, "Coordination of reactive power in grid-connected wind farms for voltage stability enhancement," IEEE Trans. Power Syst., vol. 29, no. 5, pp. 2381-2390, Sept. 2014

[19] E. Vittal, M. O'Malley, and A. Keane, "A steady-state voltage stability analysis of power systems with high penetrations of wind," IEEE Trans. Power Syst., vol. 25, no. 1, pp. 433-442, Feb. 2010.

[20] W. Qiao, R. G. Harley, and G. K. Venayagamoorthy, "Coordinated reactive power control of a large wind farm and a STATCOM using heuristic dynamic programming," IEEE Trans. Energy Convers., vol. 24, no. 2, pp. 493-503, Jun. 2009.

[21] G. Tapia, A. Tapia, and J. X. Ostolaza, "Proportional-integral regulatorbased approach to wind farm reactive power management for secondary voltage control," IEEE Trans. Energy Convers., vol. 22, no. 2, pp. 488498, Jun. 2007.

[22] H. Zhao, Q. Wu, J. Wang, Z. Liu, M. Shahidehpour, and Y. Xue, "Combined active and reactive power control of wind farms based on model predictive control," IEEE Trans. Energy Convers., vol. 32, no. 3, pp. 1177-1187, Sept. 2017.

[23] X. Ye, Z. Lu, Y. Qiao, J. Li, F. Wang, and W. Luo, "A primary analysis on mechanism of large scale cascading trip-off of wind turbine generators," Automation of Electric Power Systems, vol. 36, no. 8, pp. 11-17, Apr. 2012.

[24] T. Ding, Q. Guo, R. Bo, H. Sun, and B. Zhang, "A static voltage security region for centralized wind power integrationpart i: Concept and method," Energies, vol. 7, no. 1, pp. 420-443, Jan. 2014.

[25] T. Ding, Q. Guo, R. Bo, H. Sun, B. Zhang, and T.-e. Huang, "A static voltage security region for centralized wind power integrationpart ii: Applications," Energies, vol. 7, no. 1, pp. 444-461, Jan. 2014.

[26] T. Ding, R. Bo, H. Sun, F. Li, and Q. Guo, "A robust two-level coordinated static voltage security region for centrally integrated wind farms," IEEE Trans. Smart Grid, vol. 7, no. 1, pp. 460-470, Jan. 2016.

[27] T. Niu, Q. Guo, H. Sun, Q. Wu, B. Zhang, and T. Ding, "Autonomous voltage security regions to prevent cascading trip faults in wind turbine generators," IEEE Trans. Sustain. Energy, vol. 7, no. 3, pp. 1306-1316, Jul. 2016.

[28] T. Niu, Q. Guo, H. Jin, H. Sun, B. Zhang, and H. Liu, "Dynamic reactive power optimal allocation to decrease wind power curtailment in a large-scale wind power integration area," IET Renewable Power Generation, vol. 11, no. 13, pp. 1667-1678, Aug. 2017.

[29] W. Xiao, K. Torchyan, M. S. El Moursi, and J. L. Kirtley, "Online supervisory voltage control for grid interface of utility-level pv plants," IEEE Trans. Sustain. Energy, vol. 5, no. 3, pp. 843-853, Jul. 2014.

[30] M. S. El Moursi, W. Xiao, and J. L. Kirtley Jr, "Fault ride through capability for grid interfacing large scale pv power plants," IET Generation, Transmission \& Distribution, vol. 7, no. 9, pp. 1027-1036, Sept. 2013.

[31] N. Al Awadhi and M. S. El Moursi, "A novel centralized pv power plant controller for reducing the voltage unbalance factor at transmission level interconnection," IEEE Trans. Energy Convers., vol. 32, no. 1, pp. 233-243, Mar. 2017.

[32] T. Niu, Q. Guo, H. Sun, B. Wang, and B. Zhang, "Robust voltage control strategy for hybrid ac/dc sending-side systems to prevent cascading trip failures," IEEE Trans. Sustain. Energy, 2018.

[33] M. Jiang, Q. Guo, and H. Sun, "Day-ahead voltage scheduling method based on a two-stage robust optimisation for vsc-hvdc connected wind farms," IET Renewable Power Generation, 2018.

[34] R. Bravo, R. Yinger, D. Chassin, H. Huang, N. Lu, I. Hiskens, and G. Venkataramanan, "Load modeling transmission research," California Energy Commission, Tech. Rep, Mar. 2010.

[35] Western Electricity Coordinating Council, "NERC/WECC planning standards," Salt Lake City, UT, USA, Apr. 2003.

[36] H. Liu, V. Krishnan, J. D. McCalley, and A. Chowdhury, "Optimal planning of static and dynamic reactive power resources," IET Gener. Transm. Distrib., vol. 8, no. 12, pp. 1916-1927, Dec. 2014.

[37] B. Sapkota and V. Vittal, "Dynamic var planning in a large power system using trajectory sensitivities," IEEE Trans. Power Syst., vol. 25, no. 1, pp. 461-469, Feb. 2010.

[38] V. Krishnan, H. Liu, and J. D. McCalley, "Coordinated reactive power planning against power system voltage instability," in IEEE PES Power Systems Conference and Exposition. IEEE, Mar. 2009, pp. 1-8.

[39] J. Qi, W. Huang, K. Sun, and W. Kang, "Optimal placement of dynamic var sources by using empirical controllability covariance," IEEE Trans. Power Syst., vol. 32, no. 1, pp. 240-249, Jan. 2017.

[40] A. Tiwari and V. Ajjarapu, "Optimal allocation of dynamic var support using mixed integer dynamic optimization," IEEE Trans. Power Syst., vol. 26, no. 1, pp. 305-314, Feb. 2011.

[41] M. Paramasivam, A. Salloum, V. Ajjarapu, V. Vittal, N. B. Bhatt, and S. Liu, "Dynamic optimization based reactive power planning to mitigate slow voltage recovery and short term voltage instability," IEEE Trans. Power Syst., vol. 28, no. 4, pp. 3865-3873, Nov. 2013.

[42] Y. Xu, Z. Y. Dong, K. Meng, W. F. Yao, R. Zhang, and K. P. Wong, "Multi-objective dynamic var planning against short-term voltage instability using a decomposition-based evolutionary algorithm," IEEE Trans. Power Syst., vol. 29, no. 6, pp. 2813-2822, Nov. 2014.

[43] S. Wildenhues, J. L. Rueda, and I. Erlich, "Optimal allocation and sizing of dynamic var sources using heuristic optimization," IEEE Trans. Power Syst., vol. 30, no. 5, pp. 2538-2546, Sept. 2015.

[44] Z. H. Rather, Z. Chen, P. Thgersen, and P. Lund, "Dynamic reactive power compensation of large-scale wind integrated power system," IEEE Trans. Power Syst., vol. 30, no. 5, pp. 2516-2526, Sept. 2015.

[45] W. Huang, K. Sun, J. Qi, and Y. Xu, "A new approach to optimization of dynamic reactive power sources addressing FIDVR issues," in IEEE Power and Energy Society General Meeting, Jul. 2014, pp. 1-5.

[46] W. Huang, K. Sun, J. Qi, and Y. Xu, "Voronoi diagram based optimization of dynamic reactive power sources," in IEEE Power and Energy Society General Meeting, Jul. 2015, pp. 1-5.

[47] M. Parniani, J. H. Chow, L. Vanfretti, B. Bhargava, and A. Salazar, "Voltage stability analysis of a multiple-infeed load center using phasor measurement data," in IEEE PES Power Systems Conference and Exposition, Oct. 2006, pp. 1299-1305.

[48] S. M. Abdelkader and D. J. Morrow, "Online tracking of Thévenin equivalent parameters using PMU measurements," IEEE Trans. Power Syst., vol. 27, no. 2, pp. 975-983, May 2012.

[49] S. Corsi and G. N. Taranto, "A real-time voltage instability identification algorithm based on local phasor measurements," IEEE Trans. Power Syst., vol. 23, no. 3, pp. 1271-1279, Aug. 2008.

[50] S. Burchett, D. Douglas, S. G. Ghiocel, M. Liehr, J. H. Chow, D. Kosterev, A. Faris, E. Heredia, and G. H. Matthews, "An optimal thévenin equivalent estimation method and its application to the voltage stability analysis of a wind hub," IEEE Trans. Power Syst., vol. PP, no. 99, pp. 1-1, 2017.

[51] E. Troester, "New German grid codes for connecting PV systems to the medium voltage power grid," in 2nd Int. workshop concentrating photovoltaic power plants: optical design, production, grid connection, 2009, pp. 9-10.

[52] M. Kraiczy, L. A. Fakhri, T. Stetz, and M. Braun, "Do it locally: Local voltage support by distributed generation A management summary," IEA PVPS Task 14, Tech. Rep., Jan. 2010.

[53] "IEEE Standard for Interconnecting Distributed Resources with Electric Power Systems - Amendment 1," IEEE Std 1547a-2014 (Amendment to IEEE Std 1547-2003), pp. 1-16, May 2014.

[54] "IEEE Standard for Interconnection and Interoperability of Distributed Energy Resources with Associated Electric Power Systems Interfaces," IEEE Std 1547-2018, pp. 36-41, 2018. 
[55] American National Standards Institute (ANSI), "American National Standard for Electric Power Systems and EquipmentVoltage Ratings $(60 \mathrm{~Hz}), "$ Standard.

[56] "IEEE Volt Var Task Force Basic C84.1 Considerations for Distributed Resources," 2017.

[57] Hydro One Networks Inc., "Distributed generation technical interconnection requirements: Interconnections at voltages $50 \mathrm{kV}$ and below," Tech. Rep., Mar. 2013.

[58] P. M. S. Carvalho, P. F. Correia, and L. A. F. M. Ferreira, "Distributed reactive power generation control for voltage rise mitigation in distribution networks," IEEE Trans. Power Syst., vol. 23, no. 2, pp. 766-772, May 2008.

[59] R. Tonkoski, D. Turcotte, and T. H. El-Fouly, "Impact of high PV penetration on voltage profiles in residential neighborhoods," IEEE Trans. Sustain. Energy, vol. 3, no. 3, pp. 518-527, 2012.

[60] L. Cheng, Y. Chang, and R. Huang, "Mitigating voltage problem in distribution system with distributed solar generation using electric vehicles," IEEE Trans. Sustain. Energy, vol. 6, no. 4, pp. 1475-1484, Oct. 2015.

[61] M. Zeraati, M. E. H. Golshan, and J. M. Guerrero, "A consensus-based cooperative control of pev battery and PV active power curtailment for voltage regulation in distribution networks," IEEE Trans. Smart Grid, vol. PP, no. 99, pp. 1-1, 2017.

[62] S. Acharya, M. S. El Moursi, A. Al-Hinai, A. S. Al-Sumaiti, and H. Zeineldin, "A control strategy for voltage unbalance mitigation in an islanded microgrid considering demand side management capability," IEEE Trans. Smart Grid, 2018.

[63] K. Clement-Nyns, E. Haesen, and J. Driesen, "The impact of charging plug-in hybrid electric vehicles on a residential distribution grid," IEEE Trans. Power Syst., vol. 25, no. 1, pp. 371-380, Feb. 2010.

[64] "Rule 21 Interconnection Standard, CA." [Online]. Available: http://www.cpuc.ca.gov/General.aspx?id=3962

[65] D. Divan, R. Moghe, and H. Chun, "Managing distribution feeder voltage issues caused by high PV penetration," in IEEE 7th Int. Symposium on Power Electronics for Distributed Generation Systems, Jun. 2016, pp. 1-8.

[66] J. von Appen, M. Braun, T. Stetz, K. Diwold, and D. Geibel, "Time in the sun: the challenge of high PV penetration in the German electric grid," IEEE Power and Energy Magazine, vol. 11, no. 2, pp. 55-64, 2013.

[67] S. Martinenas, K. Knezovic, and M. Marinelli, "Management of power quality issues in low voltage networks using electric vehicles: Experimental validation," IEEE Trans. Power Delivery, vol. 32, no. 2, pp. 971-979, Apr. 2017.

[68] A. T. Al-Awami, E. Sortomme, G. M. A. Akhtar, and S. Faddel, "A voltage-based controller for an electric-vehicle charger," IEEE Trans. Veh. Technol., vol. 65, no. 6, pp. 4185-4196, Jun. 2017.

[69] S. Chalise, H. R. Atia, B. Poudel, and R. Tonkoski, "Impact of active power curtailment of wind turbines connected to residential feeders for overvoltage prevention," IEEE Trans. Sustain. Energy, vol. 7, no. 2, pp. 471-479, 2016.

[70] R. Tonkoski, L. Lopes, and T. El-Fouly, "Coordinated active power curtailment of grid connected PV inverters for overvoltage prevention," IEEE Trans. Sustain. Energy, vol. 2, no. 2, pp. 139-147, 2011.

[71] J. M. Guerrero, J. Matas, L. G. de Vicuna, M. Castilla, and J. Miret, "Decentralized control for parallel operation of distributed generation inverters using resistive output impedance," IEEE Trans. Ind. Electron., vol. 54, no. 2, pp. 994-1004, 2007.

[72] Y. Wang, P. Zhang, W. Li, W. Xiao, and A. Abdollahi, "Online overvoltage prevention control of photovoltaic generators in microgrids," IEEE Trans. Smart Grid, vol. 3, no. 4, pp. 2071-2078, 2012.

[73] S. Alyami, Y. Wang, C. Wang, J. Zhao, and B. Zhao, "Adaptive real power capping method for fair overvoltage regulation of distribution networks with high penetration of PV systems," IEEE Trans. Smart Grid, vol. 5, no. 6, pp. 2729-2738, 2014.

[74] D. Wu, F. Tang, T. Dragicevic, J. C. Vasquez, and J. M. Guerrero, "Autonomous active power control for islanded ac microgrids with photovoltaic generation and energy storage system," IEEE Trans. Energy Convers., vol. 29, no. 4, pp. 882-892, 2014.

[75] K. Baker, A. Bernstein, E. Dall'Anese, and C. Zhao, "Networkcognizant voltage droop control for distribution grids," IEEE Trans. Power Syst., vol. 33, no. 2, pp. 2098-2108, Mar. 2018.

[76] A. Kiprakis and A. Wallace, "Maximising energy capture from distributed generators in weak networks," IEE Proceedings-Gener Transm. Distrib., vol. 151, no. 5, pp. 611-618, 2004.
[77] T. Sansawatt, J. O'Donnell, L. F. Ochoa, and G. P. Harrison, "Decentralised voltage control for active distribution networks," in 44th Int. Universities Power Engineering Conference (UPEC), 2009, pp. 1-5.

[78] F. Olivier, P. Aristidou, D. Ernst, and T. Van Cutsem, "Active management of low-voltage networks for mitigating overvoltages due to photovoltaic units," IEEE Trans. Smart Grid, vol. 7, no. 2, pp. 926936, 2016.

[79] H. Gao, J. Liu, L. Wang, and Z. Wei, "Decentralized energy management for networked microgrids in future distribution systems," IEEE Trans. Power Syst., vol. PP, no. 99, pp. 1-1, 2017.

[80] S. Weckx, R. DHulst, B. Claessens, and J. Driesen, "Multiagent charging of electric vehicles respecting distribution transformer loading and voltage limits," IEEE Trans. Smart Grid, vol. 5, no. 6, pp. 28572867, Nov. 2014.

[81] B. A. Robbins, C. N. Hadjicostis, and A. D. Domínguez-García, "A two-stage distributed architecture for voltage control in power distribution systems," IEEE Trans. Power Syst., vol. 28, no. 2, pp. 1470-1482, May 2013.

[82] Z. Li, Q. Guo, H. Sun, J. Wang, Y. Xu, and M. Fan, "A distributed transmission-distribution-coupled static voltage stability assessment method considering distributed generation," IEEE Trans. Power Syst. vol. 33, no. 3, pp. 2621-2632, May 2018.

[83] P. N. Vovos, A. E. Kiprakis, A. R. Wallace, and G. P. Harrison, "Centralized and distributed voltage control: Impact on distributed generation penetration," IEEE Trans. Power Syst., vol. 22, no. 1, pp. 476-483, 2007.

[84] P. Richardson, D. Flynn, and A. Keane, "Local versus centralized charging strategies for electric vehicles in low-voltage distribution systems," IEEE Trans. Smart Grid, vol. 3, no. 2, pp. 1020-1028, Jun. 2012.

[85] A. Shafiu, T. Bopp, I. Chilvers, and G. Strbac, "Active management and protection of distribution networks with distributed generation," in IEEE Power Engineering Society General Meeting, Jun. 2004, pp. 1098-1103.

[86] G. Valverde and T. Van Cutsem, "Model predictive control of voltages in active distribution networks," IEEE Trans. Smart Grid, vol. 4, no. 4, pp. 2152-2161, Dec. 2013.

[87] M. Juamperez, Y. Guangya, and S. Kjær, "Voltage regulation in lv grids by coordinated volt-var control strategies," Journal of Modern Power Systems and Clean Energy, vol. 2, no. 4, pp. 319-328, Dec. 2014.

[88] S. Corsi, "Voltage control on distribution smart grids," in Voltage Control and Protection in Electrical Power Systems. Springer, 2015, pp. $465-495$.

[89] P. Richardson, D. Flynn, and A. Keane, "Optimal charging of electric vehicles in low-voltage distribution systems," IEEE Trans. Power Syst., vol. 27, no. 1, pp. 268-279, Feb. 2012.

[90] A. OConnell, D. Flynn, and A. Keane, "Rolling multi-period optimization to control electric vehicle charging in distribution networks," IEEE Trans. Power Syst., vol. 29, no. 1, pp. 340-348, Jan. 2014.

[91] J. Quiros-Tortos, L. Ochoa, S. Alnaser, and T. Butler, "Control of ev charging points for thermal and voltage management of lv networks," IEEE Trans. Power Syst., vol. 31, no. 4, pp. 3028-3039, Jul. 2016.

[92] D. E. Olivares, A. Mehrizi-Sani, A. H. Etemadi, C. A. Cañizares, R. Iravani, M. Kazerani, A. H. Hajimiragha, O. Gomis-Bellmunt, M. Saeedifard, R. Palma-Behnke et al., "Trends in microgrid control," IEEE Trans. Smart Grid, vol. 5, no. 4, pp. 1905-1919, 2014.

[93] J. M. Guerrero, J. C. Vasquez, J. Matas, L. G. De Vicuña, and M. Castilla, "Hierarchical control of droop-controlled ac and dc microgridsa general approach toward standardization," IEEE Trans. Ind. Electron., vol. 58, no. 1, pp. 158-172, 2011.

[94] J. M. Guerrero, L. G. De Vicuna, J. Matas, M. Castilla, and J. Miret, "A wireless controller to enhance dynamic performance of parallel inverters in distributed generation systems," IEEE Trans. Power Electron., vol. 19, no. 5, pp. 1205-1213, 2004.

[95] E. N. Azadani, C. Canizares, and K. Bhattacharya, "Modeling and stability analysis of distributed generation," in Power and Energy Society General Meeting, 2012 IEEE. IEEE, Jul. 2012, pp. 1-8.

[96] E. Nasr-Azadani, C. A. Caizares, D. E. Olivares, and K. Bhattacharya, "Stability analysis of unbalanced distribution systems with synchronous machine and DFIG based distributed generators," IEEE Trans. Smart Grid, vol. 5, no. 5, pp. 2326-2338, Sept. 2014.

[97] O. Gomis-Bellmunt, A. Junyent-Ferre, A. Sumper, and J. BergasJane, "Ride-through control of a doubly fed induction generator under unbalanced voltage sags," IEEE Trans. Energy Convers., vol. 23, no. 4, pp. 1036-1045, Dec. 2008. 
[98] T. Brekken, N. Mohan, and T. Undeland, "Control of a doubly-fed induction wind generator under unbalanced grid voltage conditions," in European Conf. Power Electron. Appl., Sept. 2005.

[99] B. B. Johnson, S. V. Dhople, J. L. Cale, A. O. Hamadeh, and P. T. Krein, "Oscillator-based inverter control for islanded three-phase microgrids," IEEE J. Photovolt., vol. 4, no. 1, pp. 387-395, Jan. 2014.

[100] B. Seal and M. McGranaghan, "Standard Language Protocols for PV and Storage Grid Integration," EPRI, Tech. Rep., May 2010.

[101] M. Farivar, L. Chen, and S. Low, "Equilibrium and dynamics of local voltage control in distribution systems," in IEEE 52nd Annual Conf. Decision and Control (CDC). IEEE, Dec. 2013, pp. 4329-4334.

[102] P. Jahangiri and D. C. Aliprantis, "Distributed volt/var control by PV inverters," IEEE Trans. Power Syst., vol. 28, no. 3, pp. 3429-3439, Aug 2013.

[103] H. Zhu and H. J. Liu, "Fast local voltage control under limited reactive power: Optimality and stability analysis," IEEE Trans. Power Syst., vol. 31, no. 5, pp. 3794-3803, Sept. 2016.

[104] A. Singhal, V. Ajjarapu, J. C. Fuller, and J. Hansen, "Real-time local volt/var control under external disturbances with high pv penetration," IEEE Trans. Smart Grid, pp. 1-1, 2018.

[105] M. Bello, D. M. Martinez, B. York, and J. Smith, "Optimal settings for multiple groups of smart inverters on secondary systems using autonomous control," IEEE Trans. Ind. Appl., Oct. 2017.

[106] H. Li, M. Rylander, and J. Smith, "Analysis to Inform CA Grid Integration: Methods and Default Settings to Effectively Use Advanced Inverter Functions in the Distribution System," EPRI, Tech. Rep. 3002007139, Dec. 2015

[107] M. Rylander, H. Li, J. Smith, and W. Sunderman, "Default volt-var inverter settings to improve distribution system performance," in IEEE Power and Energy Society General Meeting, Jul. 2016, pp. 1-5.

[108] J. Qi, A. Hahn, X. Lu, J. Wang, and C.-C. Liu, "Cybersecurity for distributed energy resources and smart inverters," IET Cyber-Physical Systems: Theory \& Applications, vol. 1, no. 1, pp. 28-39, Dec. 2016.

[109] R. Moghe, D. Tholomier, D. Divan, J. Schatz, and D. Lewis, "Grid edge control: A new approach for volt-var optimization," in IEEE Transm. Distrib. Conf. Exposition, May 2016, pp. 1-5.

[110] R. Moghe, D. Divan, D. Lewis, and J. Schatz, "Turning distribution feeders into statcoms," IEEE Trans. Ind. Appl., vol. 53, no. 2, pp. 1372-1380, Mar. 2017.

[111] H. E. L. Hawaiian Electric, Maui Electric, "Modernizing Hawai 'i’s grid for our customers," Tech. Rep., Jun. 2017.

[112] M. Geidl, "Implementation of coordinated voltage control for the Swiss transmission system," in 15th IEEE Mediterranean Electrotechnical Conference, Apr. 2010, pp. 230-236.

[113] M. Heleno, R. Soares, J. Sumaili, R. Bessa, L. Seca, and M. Matos, "Estimation of the flexibility range in the transmission-distribution boundary," in IEEE Eindhoven PowerTech, Jun. 2015, pp. 1-6.

[114] E. Kaempf, H. Abele, S. Stepanescu, and M. Braun, "Reactive power provision by distribution system operators-optimizing use of available flexibility," in IEEE PES Innovative Smart Grid Technologies, Europe, Oct. 2014, pp. 1-5.

[115] I. J. Perez-Arriaga, "The transmission of the future: The impact of distributed energy resources on the network," IEEE Power and Energy Magazine, vol. 14, no. 4, pp. 41-53, Jul. 2016.

[116] A. Singhal and V. Ajjarapu, "A framework to utilize DERs' var resources to support the grid in an integrated T-D system," in IEEE Power and Energy Society General Meeting, Aug. 2018.

[117] H. Barth, D. Hidalgo, A. Pohlemann, M. Braun, L. H. Hansen, and $\mathrm{H}$. Knudsen, "Technical and economical assessment of reactive power provision from distributed generators: Case study area of east denmark," in IEEE Grenoble Conference, Jun. 2013, pp. 1-6.

[118] ENTSO-E , "Network code on demand connection," Tech. Rep., 2012.

[119] D. S. Stock, A. Venzke, T. Hennig, and L. Hofmann, "Model predictive control for reactive power management in transmission connected distribution grids," in IEEE PES Asia-Pacific Power and Energy Engineering Conference (APPEEC), Oct. 2016, pp. 419-423.

[120] C. G. Kaloudas, L. F. Ochoa, B. Marshall, S. Majithia, and I. Fletcher, "Assessing the future trends of reactive power demand of distribution networks," IEEE Trans. Power Syst., vol. 32, no. 6, pp. 4278-4288, Nov. 2017

[121] L. Chen, H. Y. Li, S. Cox, and K. Bailey, "Ancillary service for transmission systems by tap stagger operation in distribution networks," IEEE Trans. Power Del., vol. 31, no. 4, pp. 1701-1709, Aug. 2016.

[122] L. Chen and H. Li, "Optimized reactive power supports using transformer tap stagger in distribution networks," IEEE Trans. Smart Grid, vol. 8, no. 4, pp. 1987-1996, July 2017.
[123] F. Marten, K. Diwold, L. Lwer, L. M. Faiella, P. Hochloff, L. H. Hansen, and M. Braun, "Analysis of a reactive power exchange between distribution and transmissiongrids," in IEEE Int. Workshop on Inteligent Energy Systems (IWIES), Nov. 2013, pp. 52-57.

[124] F. Marten, L. Lwer, J. C. Tbermann, and M. Braun, "Optimizing the reactive power balance between a distribution and transmission grid through iteratively updated grid equivalents," in Power Systems Computation Conference, Aug. 2014, pp. 1-7.

[125] N. Fonseca, J. Silva, A. Silva, J. Sumaili, L. Seca, R. Bessa, J. Pereira, M. Matos, P. Matos, A. C. Morais, M. Caujolle, and M. SebastianViana, "Evolvdso grid management tools to support TSO-DSO cooperation," in CIRED Workshop 2016, Jun. 2016, pp. 1-4.

[126] J. Morin, F. Colas, S. Grenard, J. Y. Dieulot, and X. Guillaud, "Coordinated predictive control in active distribution networks with $\mathrm{hv} / \mathrm{mv}$ reactive power constraint," in IEEE PES Innovative Smart Grid Technologies Conference Europe (ISGT-Europe), Oct 2016, pp. 1-6.

[127] S. Li, T. Yu, T. Pu, J. Ming, and S. Fan, "Coordinated optimization control method of transmission and distribution network," in IEEE PES Asia-Pacific Power and Energy Engineering Conf., Oct. 2016, pp. 2215-2219.

[128] T. Ding, C. Li, C. Huang, Y. Yang, F. Li, and F. Blaabjerg, "A hierarchical modeling for reactive power optimization with joint transmission and distribution networks by curve fitting," IEEE Syst. J., vol. PP, no. 99, pp. 1-10, 2017.

[129] Z. Li, Q. Guo, H. Sun, J. Wang, and T. Xu, "A response-functionbased coordination method for transmission-distribution-coupled AC OPF," in IEEE PES Transm. Distrib. Conf. Exposition, 2018.

[130] B. H. Kim and R. Baldick, "Coarse-grained distributed optimal power flow," IEEE Trans. Power Syst., vol. 12, no. 2, pp. 932-939, May 1997.

[131] T. Erseghe, "Distributed optimal power flow using admm," IEEE Trans. Power Syst., vol. 29, no. 5, pp. 2370-2380, Sept. 2014.

[132] A. J. Conejo, F. J. Nogales, and F. J. Prieto, "A decomposition procedure based on approximate newton directions," Mathematical programming, vol. 93, no. 3, pp. 495-515, Dec. 2002

[133] P. N. Biskas and A. G. Bakirtzis, "Decentralised OPF of large multiarea power systems," IEE Proceedings - Gener. Transm. Distrib., vol. 153 no. 1, pp. 99-105, Jan. 2006.

[134] C. Lin, W. Wu, B. Zhang, B. Wang, W. Zheng, and Z. Li, "Decentralized reactive power optimization method for transmission and distribution networks accommodating large-scale DG integration," IEEE Trans. Sustain. Energy, vol. 8, no. 1, pp. 363-373, Jan 2017.

[135] Z. Li, Q. Guo, H. Sun, and J. Wang, "Coordinated transmission and distribution AC optimal power flow," IEEE Trans. Smart Grid, vol. 9, no. 2, pp. 1228-1240, Mar. 2018.

[136] D. B. Arnold, M. D. Sankur, M. Negrete-Pincetic, and D. S. Callaway, "Model-free optimal coordination of distributed energy resources for provisioning transmission-level services," IEEE Trans. Power Syst., vol. 33, no. 1, pp. 817-828, Jan. 2018.

[137] T. Van Cutsem and C. Vournas, Voltage Stability of Electric Power Systems. Springer, 1998.

[138] P. Aristidou, G. Valverde, and T. Van Cutsem, "Contribution of distribution network control to voltage stability: A case study," IEEE Trans. Smart Grid, vol. 8, no. 1, pp. 106-116, Jan 2017.

[139] C. Vournas and T. Van Cutsem, "Local identification of voltage emergency situations," IEEE Trans. Power Syst., vol. 23, no. 3, pp. 1239-1248, Aug. 2008.

[140] E. Dall'Anese, S. Guggilam, A. Simonetto, Y. C. Chen, and S. V. Dhople, "Optimal regulation of virtual power plants," IEEE Trans. Power Syst., vol. 33, no. 2, pp. 1868-1881, Mar. 2017.

[141] A. Keane, L. Ochoa, E. Vittal, C. Dent, and G. Harrison, "Enhanced utilization of voltage control resources with distributed generation," IEEE Trans. Power Syst., vol. 26, no. 1, pp. 252-260, Feb. 2011.

[142] Z. Li, Q. Guo, H. Sun, and J. Wang, "Impact of coupled transmissiondistribution on static voltage stability assessment," IEEE Trans. Power Syst., vol. 32, no. 4, pp. 3311-3312, Jul. 2017.

[143] A. Singhal and V. Ajjarapu, "Long-term voltage stability assessment of an integrated transmission distribution system," in North American Power Symposium (NAPS), Sept. 2017, pp. 1-6.

[144] H. Sun, Q. Guo, B. Zhang, Y. Guo, Z. Li, and J. Wang, "Master-slavesplitting based distributed global power flow method for integrated transmission and distribution analysis," IEEE Trans. Smart Grid, vol. 6 , no. 3, pp. 1484-1492, May 2015.

[145] B. Palmintier et al., "IGMS: An integrated ISO-to-appliance scale grid modeling system," IEEE Trans. Smart Grid, vol. 8, no. 3, May 2017.

[146] N. Pilatte, P. Aristidou, and G. Hug, "TDNetGen: An open-source, parametrizable, large-scale, transmission, and distribution test system," IEEE Syst. J., vol. PP, no. 99, pp. 1-9, 2017. 